\title{
SISTEM PAKAR BERBASIS WEB DAN MOBILE WEB UNTUK MENDIAGNOSIS PENYAKIT DARAH PADA MANUSIA DENGAN MENGGUNAKAN METODE INFERENSI FORWARD CHAINING
}

\author{
Muhammad Silmi, Eko Adi Sarwoko, Kushartantya \\ Jurusan Ilmu Komputer / Informatika Fakultas Sains dan Matematika Universitas Diponegoro \\ Email : silmzation@gmail.com, eko.adi.sarwoko@gmail.com,kushartantya@hotmail.com
}

\begin{abstract}
ABSTRAK
Sistem pakar (expert system) secara umum adalah sistem yang berusaha mengadopsi pengetahuan manusia ke komputer yang dirancang dan diimplementasikan dengan menggunakan bahasa pemrograman tertentu agar komputer dapat menyelesaikan masalah seperti yang dilakukan oleh para ahli. Saat ini sistem pakar tengah banyak dikembangkan dalam berbagai macam bidang, salah satunya dalam bidang kesehatan. Sistem pakar dalam bidang kesehatan banyak dikembangkan untuk mendeteksi berbagai macam penyakit dengan menggunakan berbagai macam metode, salah satunya menggunakan metode inferensi forward chaining. Metode inferensi forward chaining merupakan metode inferensi penelusuran ke depan yang dibuat dengan perancangan yang mudah dan sesuai dengan aturan yang ada. Masyarakat memandang kesehatan sebagai hal yang penting, salah satunya berkait dengan penyakit darah. Pengetahuan masyarakat umum tentang penyakit darah masih minim, masyarakat masih belum dapat mengetahui ataupun menentukan penyakit darah yang dideritanya. Penelitian ini, bertujuan untuk merancang sistem pakar yang dapat mendiagnosis penyakit darah menggunakan metode inferensi forward chaining. Aplikasi ini diharapkan dapat membantu masyarakat dalam mendiagnosa jenis penyakit darah. Implementasi sistem pakar penyakit darah ini diharapkan memberikan kemudahan akses bagi penggunanya, melalui penggunaan media sarana berbasis web dan mobile web.
\end{abstract}

Kata Kunci : Sistem pakar, Penyakit darah, Forward Chaining, Web, Mobile Web.

\section{PENDAHULUAN}

Sistem pakar dalam bidang kesehatan saat ini tengah banyak dikembangkan dalam hal diagnosis penyakit, namun belum ada sistem pakar yang dapat mendiagnosis jenis penyakit darah pada manusia, sementara itu darah merupakan salah satu hal yang sangat penting bagi tubuh manusia. Darah memiliki peranan penting dalam hal transportasi zat-zat yang diperlukan tubuh dan juga memiliki fungsi dalam hal menjaga kekebalan tubuh agar tidak mudah terkena penyakit. Jumlah darah dalam tubuh manusia mencapai $6-8 \%$ dari keseluruhan berat tubuh manusia [3]. Data yang dihimpun oleh WHO (world health organization) antara tahun 1998-2005 menunjukkan bahwa $24,8 \%$ dari jumlah populasi manusia di dunia terkena anemia yang merupakan salah satu jenis penyakit darah [8].

Diagnosa penyakit darah yang tepat sangat penting bagi masyarakat yang mengindap penyakit darah untuk mendapatkan pelayanan dan perawatan medis lebih lanjut yang sesuai dengan jenis penyakit darah yang dideritanya.
Diagnosis penyakit darah yang dilakukan saat ini masih secara konvensional yakni melalui konsultasi dengan dokter. Melalui sistem pakar berbasis web dan mobile web dapat mempermudah proses diagnosa awal penyakit darah melalui akses website pada perangkat komputer ataupun perangkat internet mobile.

\section{METODOLOGI}

\subsection{Sistem Pakar}

Sistem pakar adalah sistem berbasis komputer yang menggunakan pengetahuan, fakta dan teknik penalaran dalam memecahkan masalah yang biasanya hanya dapat dipecahkan oleh seorang pakar dalam bidang tersebut [6].

Sistem pakar merupakan cabang dari Artificial Intelligence (AI) yang sudah lama karena sistem ini telah mulai dikembangkan pada pertengahan tahun 1960 [4]. Sistem pakar yang muncul pertama kali adalah Generalpurpose problem solver (GPS) yang dikembangkan oleh Newl dan Simon. Sampai saat ini sudah banyak sistem pakar yang dibuat, seperti MYCIN, DENDRAL, XCON \& XSEL, 
SOPHIE, Prospector, FOLIO, DELTA, dan sebagainya [4].

Sistem pakar (expert system) secara umum adalah sistem yang berusaha mengadopsi pengetahuan manusia ke komputer, agar komputer dapat menyelesaikan masalah seperti yang biasa dilakukan oleh para ahli.

\subsection{Struktur Sistem Pakar}

Sistem pakar disusun oleh dua bagian utama, yaitu lingkungan pengembangan (development environment) dan lingkungan konsultasi (consultation environment) [7]. Lingkungan pengembangan sistem pakar digunakan untuk memasukkan pengetahuan pakar ke dalam lingkungan sistem pakar, sedangkan lingkungan konsultasi digunakan oleh pengguna yang bukan pakar guna memperoleh pengetahuan pakar.

Bagian-bagian utama sistem pakar dapat dilihat pada Gambar 2.1. Selain terdapat dua bagian lingkungan dari sistem pakar, sistem pakar juga memiliki beberapa komponen penyusun. Komponen-komponen yang terdapat dalam sistem pakar yaitu User Interface (antarmuka pengguna), basis pengetahuan, akuisisi pengetahuan, mesin inference, workplace, fasilitas penjelasan, perbaikan pengetahuan.

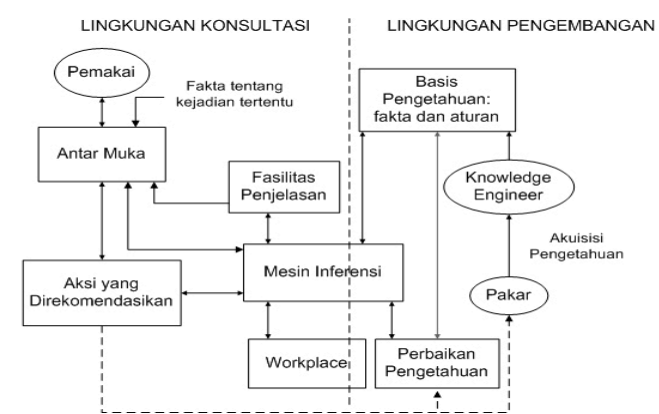

Gambar 2.1 Arsitektur Sistem Pakar

\subsection{Metode Inferensi Forward Chaining}

Metode inferensi adalah program komputer yang memberikan metodologi untuk penalaran tentang informasi yang ada dalam basis pengetahuan dan dalam workplace, dan untuk memformulasikan kesimpulan [7].

Forward chaining adalah mekanisme pencocokan fakta atau pernyataan yang dimulai dari kondisi $(I F)$ terlebih dahulu dengan aturan
(IF-THEN). Penalaran dimulai dari fakta terlebih dahulu untuk menguji kebenaran hipotesa. Ilustrasi pelacakan runut maju (forward chaining) dapat dilihat pada gambar 2.2.

\begin{tabular}{|lll|}
\hline DATA & ATURAN & KESIMPULAN \\
A $=1$ & JIKA $A=1$ DAN B $=2$ & D $=4$ \\
$\mathrm{~B}=2$ & MAKA C $=3$ & \\
& JIKA C $=3$ MAKA D $=4$ & \\
\end{tabular}

Gambar 2.2 Pelacakan Runut Maju (Forward Chaning)

\subsection{Web dan Mobile Web}

Web adalah sebuah sistem dengan informasi yang disajikan dalam bentuk teks, gambar, suara dan lain-lain yang tersimpan dalam sebuah server web internet yang disajikan dalam bentuk hiperteks [5]. Informasi lainnya disajikan dalam bentuk lain misalkan grafis (format GIF, JPG, PNG), suara (format WAV, MP3), video (format MP4, FLV) dan objek multimedia lainnya.Web dapat diakses oleh perangkat lunak client web yang disebut browser. Browser membaca halaman-halaman web yang tersimpan dalam server web melalui protokol HTTP (Hypertext Transfer Protocol).

Web sebagai sistem tentu memiliki arsitektur tersendiri. Ada dua komponen dasar dalam arsitektur web, yaitu browser web dan server web. Browser web memberikan antarmuka grafis untuk pengguna dan bertanggung jawab untuk berkomunikasi dengan server web sesuai dengan standar protokol HTTP.

Mobile web adalah sebuah website dengan tampilan yang diatur atupun disesuaikan dengandengan mobile web browser pada telepon genggam digital atau terminal mobile yang mempunyai fasilitas mobile web browser dan dapat melihat/membaca isi sebuah halaman situs dalam sebuah format teks khusus [2]. Protokol yang digunakan pada mobile web sama seperti web karena memang letak perbedaan ada pada tampilan. Untuk dapat memberikan halaman yang diberikan apakah jenis web atau mobile web dapat menggunakan kode browser agent pada halaman index.

\subsection{Penyakit Darah}

Darah merupakan hal yang sangat vital dalam tubuh, darah berfungsi untuk 
menyalurkan sari makanan, oksigen dan zat-zat kimia lain ke seluruh bagian tubuh. Selain sebagai penyalur berbagai macam zat, darah juga memiliki peran penting untuk menjaga kekebalan tubuh agar tidak mudah terserah penyakit [1]. Namun seperti yang kita ketahui, banyak juga penyakit yang menyerang tubuh melalui darah. Penyakit darah merupakan penyakit yang menyerang tubuh melalui darah. Penyakit darah memiliki berbagai macam jenis.

Penyakit darah memiliki beberapa jenis spesifikasi penyakit yang berbeda-beda. Bebera jenis penyakit pada darah yang dibangun dalam sistem pakar diagnosis penyakit darah ini antara lain adalah Anemia, leukimia, thalassemia, hemofilia, neutropenia, trombositopenia, limfoma hodgkin, makroglobulinemia, telangiektasi hemoragik herediter, sel sabit, purpura alergika, hemolitik uremik, polisitemia vera, mikosis fungoides dan eosinofilia.

\section{IDENTIFIKASI, KONSEPTUALISASI DAN FORMALISASI}

\subsection{Identifikasi}

Sistem pakar ini dibuat untuk memberikan pengetahuan diagnosa awal kepada pengguna tentang jenis penyakit darah yang diderita serta juga sebagai alat bantu bagi seorang dokter untuk dapat mengambil keputusan atau diagnosa yang tepat terhadap suatu gejala sehingga diperoleh pengobatan yang tepat.

Perancangan sistem ini meliputi:

a. Sistem mengadaptasi pemikiran pakar dalam mendiagnosa penyakit dalam yang dituangkan dalam suatu kaidah diagnosa.

b. Sistem menganalisa masukan pengguna dengan aturan yang ditetapkan.

c. Sistem dapat mengambil keputusan berdasarkan masukan dari pengguna.

d. Sistem memberikan informasi berupa pengetahuan kepada pengguna mengenai angka kemungkinan penyakit dalam yang diderita berdasarkan alur runut maju (forward chaining) dari masukan gejala yang dialami.

\subsection{Konseptualisasi}

\subsubsection{SRS}

SRS untuk sistem pakar diagnosis penyakit darah pada manusia dengan menggunakan metode inferensi backward chaining berbasis web dan mobile web dapat dilihat pada Tabel 3.1.

Tabel 3.1 SRS

\begin{tabular}{|c|l|}
\hline ID SRS & \multicolumn{1}{|c|}{ Deskripsi } \\
\hline $\begin{array}{c}\text { SRS-F- } \\
001\end{array}$ & $\begin{array}{l}\text { Pengguna dapat mendaftarkan ke sistem } \\
\text { dengan memasukkan data pengguna. }\end{array}$ \\
\hline $\begin{array}{c}\text { SRS-F- } \\
002\end{array}$ & $\begin{array}{l}\text { Pengguna dapat login sistem dengan } \\
\text { memasukkan } \text { username dan password }\end{array}$ \\
\hline $\begin{array}{c}\text { SRS-F- } \\
003\end{array}$ & $\begin{array}{l}\text { Pengguna dapat mengubah data } \\
\text { pengguna. }\end{array}$ \\
\hline $\begin{array}{c}\text { SRS-F- } \\
004\end{array}$ & $\begin{array}{l}\text { Pengguna dapat melakukan penelusuran } \\
\text { mengenai penyakit darah dan } \\
\text { mendapatkan hasil diagnosanya. }\end{array}$ \\
\hline $\begin{array}{c}\text { SRS-F- } \\
005\end{array}$ & $\begin{array}{l}\text { Pengguna dapat mengetahui informasi } \\
\text { tentang penyakit darah yang diberikan } \\
\text { pada halaman tentang penyakit darah. }\end{array}$ \\
\hline $\begin{array}{c}\text { SRS-F- } \\
006\end{array}$ & Pengguna dapat mengisi buku tamu. \\
\hline
\end{tabular}

\subsubsection{ERD}

Terdapat tujuh himpunan entitas di dalam sistem pakar diagnosis penyakit darah dengan menggunakan mesin inferensi forward chaining ini, yaitu pengguna, penyakit darah, gejala, aturan, diagnosa, buku tamu dan administrator. Himpunan entitas dapat dilihat pada Tabel 3.2.

Tabel 3.2 Himpunan Entitas

\begin{tabular}{|c|l|l|}
\hline No. & $\begin{array}{c}|c| \\
\text { Himpunan } \\
\text { Entitas }\end{array}$ & \multicolumn{1}{|c|}{ Deskripsi } \\
\hline 1. & Admin-istrator & $\begin{array}{l}\text { Berisi tentang data } \\
\text { administrator }\end{array}$ \\
\hline 2. & $\begin{array}{l}\text { Penyakit } \\
\text { Darah }\end{array}$ & $\begin{array}{l}\text { Profil data jenis penyakit } \\
\text { darah }\end{array}$ \\
\hline 3. & Gejala & $\begin{array}{l}\text { Gejala pada jenis-jenis } \\
\text { penyakit darah }\end{array}$ \\
\hline 4. & Diagnosa & Hasil jenis penyakit darah \\
\hline 5. & Pengguna & $\begin{array}{l}\text { Berisi tentang data } \\
\text { pengguna }\end{array}$ \\
\hline 6. & Aturan & $\begin{array}{l}\text { Relasi gejala dan penyakit } \\
\text { darah }\end{array}$ \\
\hline 7. & Buku Tamu & $\begin{array}{l}\text { Komentar ataupun saran } \\
\text { pengguna }\end{array}$ \\
\hline
\end{tabular}

Berdasarkan himpunan entitas pada Tabel 3.4 dapat digambarkan dalam sebuah ERD seperti pada Gambar 3.1. 


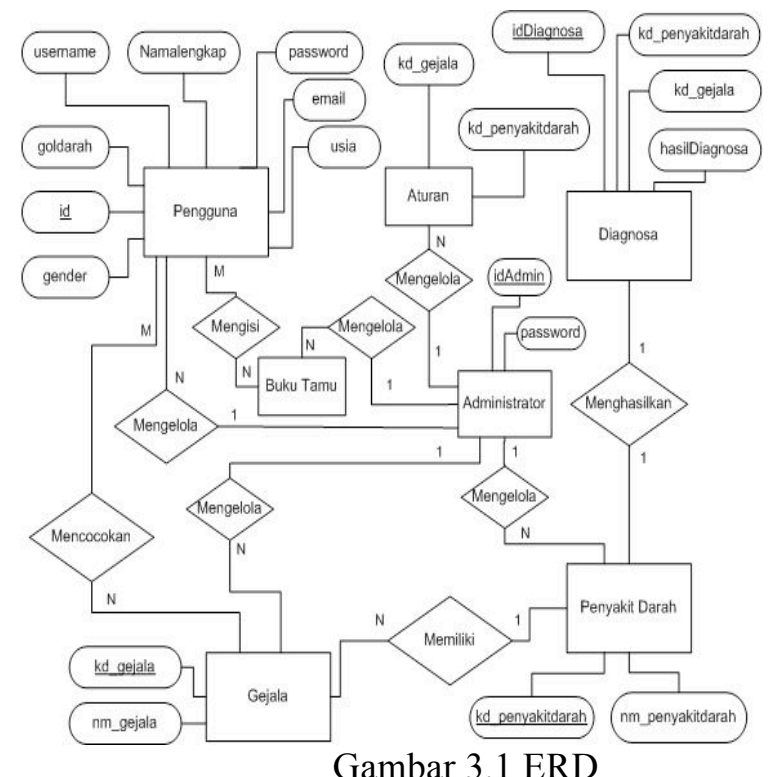

\subsubsection{DFD}

Data Flow Diagram (DFD) merupakkan diagram aliran dara yang berfungsi memetakan model lingkungan, yang dipresentasikan dengan lingkaran tunggal yang mewakili keseluruhan sistem. DFD sistem pakar ini digambarkan pada gambar 3.2.

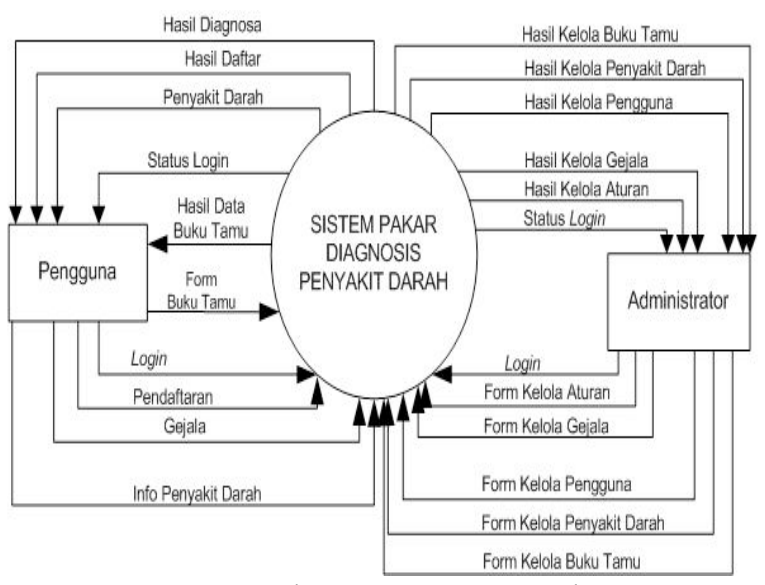

Gambar 3.2 DFD Level 0

Entitas luar yang digambarkan DCD (DFD Level 0) pada gambar 3.2 ialah pengguna dan administrator. Penjelasan entitas luar yakni administrator dan pengguna ada DFD Level 1.

1. Administrator (Dokter ataupun operator) merupakan pengelola yang dapat menginputkan data login, data gejala, data penyakit darah, data diagnosa, data pengguna dan data inferensi.
2. Pengguna (pasien) yaitu pengguna yang memberikan data sesuai dengan kecocokan gejala ke dalam sistem untuk menghasilkan diagnosa agar dapat diketahui jenis penyakit darah yang diderita ataupun bukan termasuk jenis penyakit darah.

\subsection{Formalisasi}

\subsubsection{Rancangan Antarmuka}

Rancangan antarmuka sistem pakar diagnosis penyakit darah berbasis web dan mobile web memuat beberapa navigasi halaman dibuat agar menarik dengan beberapa dekorasi gambar dan sentuhan warna merah yang melambangkan darah serta sejumlah tata letak agar pengguna dapat mudah menggunakannya.

Rancangan antarmuka halaman utama berbasis web digambarkan pada gambar 3.3, rancangan antarmuka halaman pencocokan gejala berbasis web digambarkan pada gambar 3.4 dan rancangan antarmuka halaman berbasis mobile web digambarkan pada gambar 3.5.

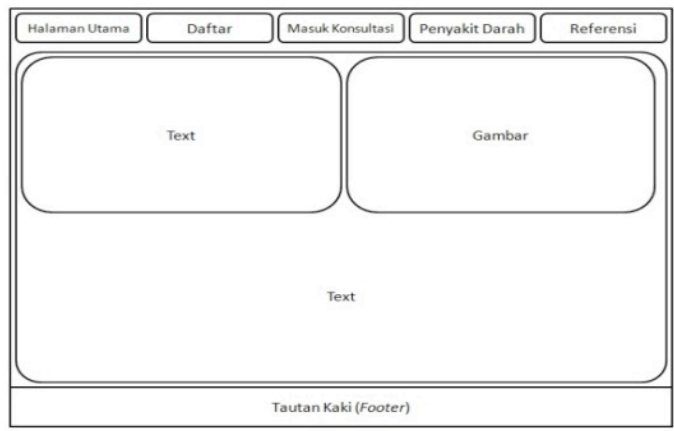

Gambar 3.3 Rancangan antarmuka halaman utama berbasis web

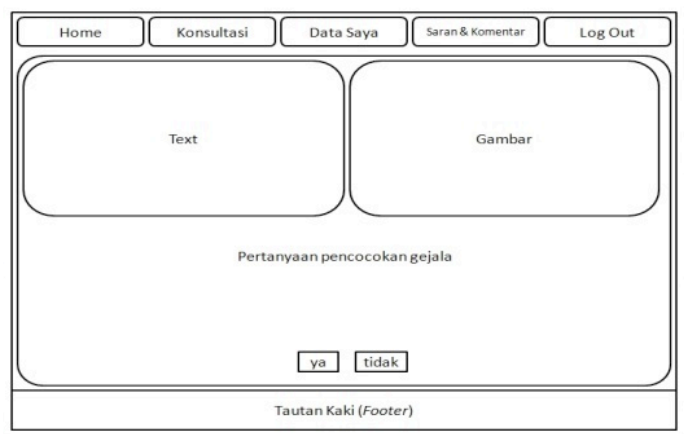

Gambar 3.4 Rancangan antarmuka halaman pencocokan gejala berbasis web 


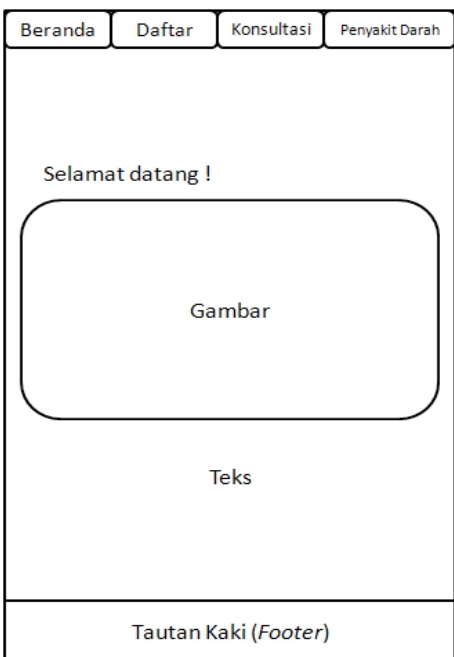

Gambar 3.5 Rancangan antarmuka halaman berbasis mobile web

\section{IMPLEMENTASI DAN EVALUASI \\ 4.1 Implementasi antarmuka}

Implementasi antarmuka merupakan transformasi dari rancangan antarmuka ke bentuk hasil jadi yang berupa halaman web yang menghubungkan pengguna, pakar ataupun administrator dengan sistem pakar diagnosis penyakit darah. Implementasi antarmuka sistem pakar diagnosis penyakit darah dibagi menjadi dua bagian yakni antarmuka berbasis web dan mobile web.

Hasil implementasi rancangan antarmuka halaman utama sistem pakar diagnosis penyakit darah berbasis web digambarkan pada gambar 4.1, implemntasi rancangan antarmuka pencocokan gejala digambarkan pada gambar 4.2 dan implementasi antarmuka berbasis mobile web digambarkan pada gambar 4.3.

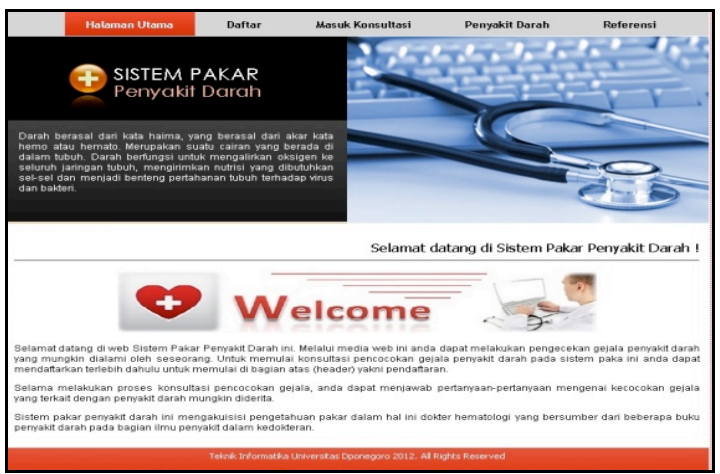

Gambar 4.1 Implementasi antarmuka halaman utama berbasis web

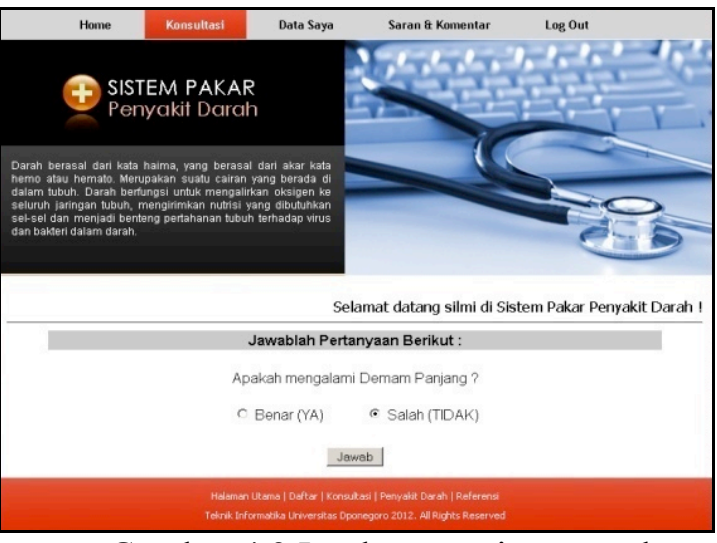

Gambar 4.2 Implementasi antarmuka halaman pencocokan gejala berbasis web

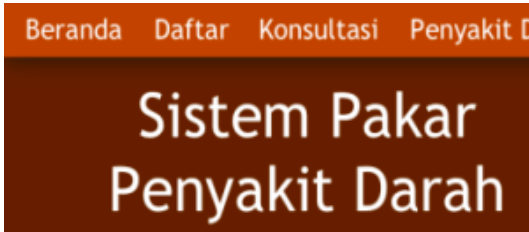

\section{Selamat Datang...}

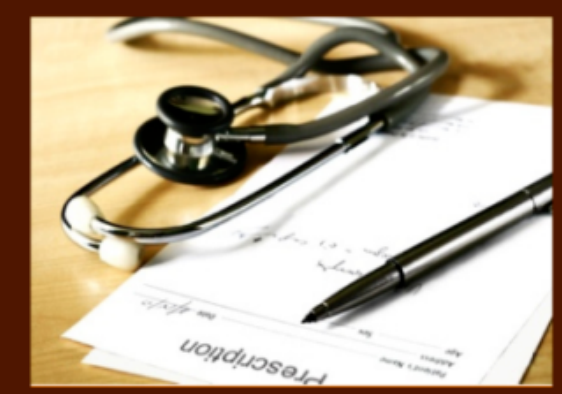

Melalui media web ini anda dapat melakukan

pengecekan gejala penyakit darah yang

Gambar 4.3 Implementasi antarmuka berbasis mobile web

\subsection{Evaluasi}

Evaluasi yang diterapkan pada sistem pakar penyakit darah ini merupakan evaluasi ataupun pengujian sesuai dengan perancangan fungsi sistem dan evaluasi terhadap evaluasi diagnosis.

\subsubsection{Evaluasi Fungsi}

Evaluasi fungsi merupakan hasil pengujian kemampuan fungsionalitas sistem untuk menangani fungsi-fungsi tertentu seseuai dengan perancangan sistem. Evaluasi fungsi dibuat berdasarkan fungsi perancangan SRS.

1. Fungsi Login Pakar 
Fungsi login pakar berhasil dibuat dan menerima masukkan data login pakar dan memberikan status login berhasil.

2. Fungsi Kelola Sistem Pakar

Fungsi sistem pakar berhasil dibuat, fungsi ini merupakan kelola sistem pakar oleh admin untuk mengelola berbagai data gejala, penyakit darah, pengguna, buku tamu dan relasi.

3. Fungsi Pendaftaran Pengguna

Fungsi Pendaftaran bagi pengguna berhasil dibuat untuk memberikan form data pendaftaran pengguna dan memasukkan data pengguna kepada sistem.

4. Fungsi Diagnosis

Fungsi diagnosis berhasil dibuat yakni fungsi untuk memberikan hasil diagnosis jenis penyakit darah setelah melakukan pencocokan gejala.

5. Fungsi Deteksi Mobile Web

Fungsi deteksi mobile web berhasil dibuat untuk dapat memberikan halaman mobile web berdasarkan mobile browser yang digunakan.

6. Fungsi Buku Tamu

Fungsi buku tamu berhasil dibuat untuk dapat menyimpan data saran ataupun komentar pengguna.

\subsubsection{Evaluasi Hasil Diagnosis}

Evaluasi hasil diagnosis merupakan hasil pengujian dari kemampuan diagnosis sistem sesuai dengan pengetahuan yang diakuisisi ke dalam sistem dan diharapkan memiliki nilai akurasi yang cukup baik.

Pengujian diagnosis sistem pakar ini dilakukan dengan uji coba contoh acak yang diterapkan untuk menguji kesesuaian gejala dan diagnosis yag sebenarnya. Pengujian ini mengambil contoh pasien penyakit darah yang memiliki jenis dan gejala penyakit darah berbeda-beda. Penulis menguji 10 sample untuk melakukan uji coba, setelah uji coba tersebut dihasilkan 8 sample adalah benar menderita jenis penyakit darah yang sesuai diagnosanya yang berarti tingkat akurasinya mencapai $80 \%$. Hasil evaluasi pengujian diagnosis sistem pakar ini dijelaskan pada tabel 4.1.
Tabel 4.1 Hasil Diagnosis

\begin{tabular}{|c|l|l|l|}
\hline No. & Sample & $\begin{array}{c}\text { Hasil } \\
\text { Diagnosis Sistem }\end{array}$ & \multicolumn{1}{|c|}{ Diagnosis } \\
\hline 1. & Sample 1 & Eosinofilia & Eosinofilia \\
\hline 2. & Sample 2 & Trombostopenia & $\begin{array}{l}\text { Trombos- } \\
\text { topenia }\end{array}$ \\
\hline 3. & Sample 3 & Hemoliti Uremik & $\begin{array}{l}\text { Makroglo- } \\
\text { bulinemia }\end{array}$ \\
\hline 4. & Sample 4 & Hemofilia & Hemofilia \\
\hline 5. & Sample 5 & Leukimia & Leukimia \\
\hline 6. & Sample 6 & $\begin{array}{l}\text { Mikosis } \\
\text { Fungoides }\end{array}$ & $\begin{array}{l}\text { Mikosis } \\
\text { Fungoides }\end{array}$ \\
\hline 7. & Sample 7 & Neutropenia & Leukimia \\
\hline 8. & Sample 8 & Hemolitik Uremik & $\begin{array}{l}\text { Hemolitik } \\
\text { Uremik }\end{array}$ \\
\hline 9. & Sample 9 & Anemia & Anemia \\
\hline 10. & Sample 10 & Polisitemia Vera & $\begin{array}{l}\text { Polisitemia } \\
\text { Vera }\end{array}$ \\
\hline
\end{tabular}

\section{KESIMPULAN DAN SARAN}

\subsection{Kesimpulan}

1. Sistem pakar ini dapat mengakuisisi pengetahuan pakar dan memberikan hasil diagnosa awal jenis penyakit darah dan dapat menyajikan fasilitas bagi pemakainya yakni pakar administrator, pengguna serta dokter.

2. Sistem ini mempunyai dua pemakai yaitu administrator dan pengguna umum. Pakar administrator dapat melakukan olah data pada sistem. Olah data meliputi input data gejala, penyakit darah dan aturan relasi, sedangkan pengguna umum dapat menggunakan sistem ini untuk mengetahui jenis penyakit darah yang mungkin diderita dan mengetahui informasi mengenai penyakit darah melalui browser komputer yang terhubung dengan jaringan internet ataupun mobile device pengguna yang dilengkapi mobile web browser sehingga memudahkan pengguna.

\subsection{Saran}

1. Pengetahuan jenis penyakit darah dalam sistem ini baru terdapat 15 jenis penyakit, masih dapat dilakukan pengembangan jenis penyakit darah yang berhubungan dengan sistem organ lainnya pada manusia yang telah diketahui, penyebab maupun gejala klinisnya.

2. Sistem ini dapat dikembangkan dengan metode lainnya agar mendapatkan hasil yang mendekati sempurna, termasuk dapat menerima masukkan data hasil laboraturium akan darah seseorang dan dapat digunakan 
sebagai data pendukung untuk menentukan diagnosis penyakit darah yang lebih spesifik jenisnya.

\section{DAFTAR PUSTAKA}

[1] Ahira, Anne. 2011. Penyakit darah. http://www.anneahira.com/penyakit-darah7372.htm ( Diakses tanggal 15 Maret 2012).

[2] Akhmadi, Ardiansyah, 2003, Aplikasi Pemrograman MOBILE WEB. Jakarta. PT. Elex Media Komputindo.

[3] Aryadnyani. 2009. Pengertian Hematologi. http://materihematologi.blogspot.com (Diakses tanggal 15 Maret 2012).
[4] Kusrini, 2006. Sistem Pakar Teori dan Aplikasi. Yogyakarta : Andi Offset.

[5] Simarmata, Janner. 2010. Rekayasa Web. yogyakarta : Andi Offset.

[6] Tolle, Herman. Pengantar Sistem Pakar. http://informatika-unkris.ac.id/img/ buku/sistem-pakar-5.pdf (Diakses tanggal 14 Maret 2012).

[7] Turban, E., 2005. Decision Support System and Intelligent System. Yogyakarta : Andi.

[8] WHO. 2012. Worldwide Prevalence on Anaemia 1998-2005. http:// who.int/vmnis/ database/anaemia/anaemia_status_summary /en/index.html (Diakses tanggal 18 November 2012). 
Sistem Pakar Berbasis Web dan Mobile Web ... 